A Brief History of Fascist Lies 



\title{
A Brief History of Fascist Lies
}

\author{
Federico Finchelstein
}

廿 UNIVERSITY OF CALIFORNIA PRESS 
University of California Press

Oakland, California

(C) 2020 by Federico Finchelstein

Library of Congress Cataloging-in-Publication Data

Names: Finchelstein, Federico, 1975- author.

Title: A brief history of fascist lies / Federico Finchelstein.

Description: Oakland, California : University of California Press, [2020] | Includes bibliographical references and index.

Identifiers: LC C N 2019052243 (print) | LC C N 2019052244 (ebook) | IS BN 9780520346710 (cloth) | IS BN 9780520975835 (epub)

Subjects: LC S H: Fascism-History-2oth century.

Classification: LC C JC481 .F 51772020 (print) | LC C JC481 (ebook) | D D C $320.53 / 3-\mathrm{dc} 23$

LC record available at https://lccn.loc.gov/2019052243

LC ebook record available at https://lccn.loc.gov/2019052244

Manufactured in the United States of America

$\begin{array}{lllllllll}28 & 27 & 26 & 25 & 24 & 23 & 22 & 21 & 20\end{array}$

$\begin{array}{llllllllll}10 & 9 & 8 & 7 & 6 & 5 & 4 & 3 & 2 & 1\end{array}$ 
A Lucia, Gabi, y Laura 
